See discussions, stats, and author profiles for this publication at: https://www.researchgate.net/publication/263829521

\title{
3D Capture, Processing, Display, and Perception with Digital Holography: Results from a European-Funded Project
}

Conference Paper · May 2011

DOI: 10.1364/DH.2011.DMC1

\section{CITATIONS}

0

9 authors, including:

Claas Falldorf

Bremer Institut für angewandte Strahltechnik $\mathrm{GmbH}$

146 PUBLICATIONS 1,030 CITATIONS

SEE PROFILE

Pietro Ferraro

Italian National Research Council

845 PUBLICATIONS 12,741 CITATIONS

SEE PROFILE

Some of the authors of this publication are also working on these related projects:

Metrology with digital holography View project

Project Phase Imaging View project
READS

91

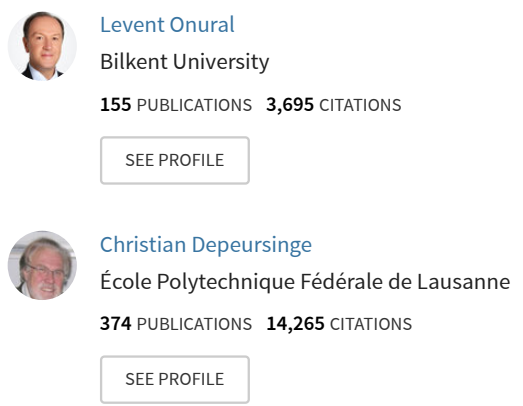




\title{
3D capture, processing, display, and perception with digital holography: results from a European-funded project
}

\author{
Thomas J. Naughton ${ }^{8,1}$, Claas Falldorf ${ }^{2}$, Levent Onural ${ }^{3}$, \\ Pietro Ferraro $^{4}$, Christian Depeursinge ${ }^{5}$, Sven Krueger ${ }^{6}$, \\ Yves Emery $^{7}$, Bryan M. Hennelly ${ }^{8}$, and Małgorzata Kujawiñska ${ }^{9}$ \\ ${ }^{1}$ Oulu Southern Institute, University of Oulu, 84100 Ylivieska, Finland. Email: firstname.lastname@oulu.fi \\ ${ }^{2}$ BIAS - Bremer Institut für Angewandte Strahltechnik Gmbh, Bremen, Germany \\ ${ }^{3}$ Electrical and Electronics Engineering Department, Bilkent University, Ankara, Turkey \\ ${ }^{4}$ Istituto Nazionale di Ottica Applicata, Consiglio Nazionale delle Ricerche, Napoli, Italy \\ ${ }^{5}$ Advanced Photonics Laboratory, École Polytechnique Fédérale de Lausanne, Switzerland \\ ${ }^{6}$ HOLOEYE Photonics AG, 12489 Berlin, Germany \\ ${ }^{7}$ Lyncée Tec Inc, 1015 Lausanne, Switzerland \\ ${ }^{8}$ Department of Computer Science, National University of Ireland Maynooth, Ireland \\ ${ }^{9}$ Faculty of Mechatronics/Institute of Micromechanics and Photonics, Warsaw University of Technology, Poland
}

\begin{abstract}
Digital holography for 3D and 4D real-world objects' capture, processing, and display" (acronym "Real 3D") is a research project funded under the Information and Communication Technologies theme of the European Commission's Seventh Framework Programme, and brings together nine participants from academia and industry (see www.digitalholography.eu). This three-year project contributes to a long-term effort to facilitate the greater presence of digital holography in the three-dimensional capture and display markets. At the end of its third year, the aims and results of the project are summarized.
\end{abstract}

(C) 2011 Optical Society of America

OCIS codes: 090.1995, 090.2870.

\section{Introduction}

Current and newly-developed 3D displays have the disadvantage of requiring special eyewear, limit the number of simultaneous viewers, discard completely certain depth cues (such as blurring) thus causing fatigue, or else encode only a small number of distinct different views. It can be argued that there is only one known technology that can capture a full 3D scene in a single shot, including phase information, and re-project that light field perfectly thus overcoming all of the above disadvantages: the broad class of holographic techniques. All other techniques are 3D only under a whole host of conditions. Unfortunately, conventional holograms are not dynamic.

The project "Digital holography for 3D and 4D real-world objects' capture, processing, and display" is funded under the Information and Communication Technologies theme of the European Commission's Seventh Framework Programme, and brings together nine participants from academia and industry. This three-year project contributes to a long-term effort to facilitate the greater presence of digital holography in the three-dimensional capture and display markets. Specifically, it is charged with eliminating current obstacles to achieving fully functional 3D video capture and display with digital holography for unrestricted viewing of real-world objects that employs all real 3D principles, hence our acronym "Real 3D."

\section{Outputs}

The primary outputs of the project are:

Output 1. A 3D holographic acquisition system based on digital camera technology, arranged nonuniformly in a circular configuration around a space of diameter $10 \mathrm{~cm}$ that will be capable of holding a dynamic real-world 3D scene. The acquisition system will be capable of recording holographic video of the 3D scene.

Output 2. A 3D holographic display system based on liquid crystal on silicon (LCOS) technology, arranged nonuniformly in a circular configuration of diameter of at least $10 \mathrm{~cm}$. The reconstruction system will be capable of displaying holographic video of the 3D scene. 
Output 3. The signal/image/information processing theories, techniques, and tools required for the processing, analysis, and synthesis of the data from capture to display, including adapting the data captured for display on alternative configurations and on conventional 3D displays. This includes holographic data of both microscopic and macroscopic 3D scenes.

Output 4. Reports containing the hard scientific data, in terms of functionality, performance, resolution, restrictions, data quality, and visual perception, that would be required by a company to take our proof-of-concept outputs and develop the next stage in the commercialisation of this 3D technology. In addition, reports on the theories, techniques, and tools that enable this technology.

\section{Demonstrators}

To demonstrate the outputs in action, and to demonstrate robust implementations of some of the project results [131], we have developed functional models of four digital holographic 3D capture, processing, and display scenarios, encompassing (i) a model for the full $360^{\circ}$ range of perspectives of reflective dynamic macroscopic 3D scenes, (ii) microscopic reflective 3D scenes, (iii) transmissive or partially transmissive microscopic 3D scenes, and (iv) capture of 3D scenes at infra-red wavelengths.

(i) A compact multi-camera hologram capture device has been developed, hologram requirements have been specified to maximise viewer impact, an integrated framework of hologram processing (dc, twin, noise removal) and hologram video compression has been developed, a circular optoelectronic display-side configuration has been fully specified and implemented, and a suite of appropriate visual perception tests has been designed.

(ii) Holograms of microscopic objects have been captured with dual wavelengths to allow phase unwrapping of larger discontinuities, the data has been processed to admit extended focus images and reconstructions on tilted planes, and the data has been conditioned for conventional stereo displays.

(iii) A two-axis rotation setup for microscopic objects has been implemented and data has been captured of transmissive biological specimens. On the processing side, a tomographic reconstruction algorithm has been finalised to accurately obtain volumetric data. For display, multi-color holographic reconstructions from phase-only SLMs have been obtained using LED illumination.

(iv) Holograms have been acquired in the infrared and promising applications have been demonstrated at different scales. The advantages of a long wavelength and wide range of transparent materials have been demonstrated with the capture of person sized objects and with the imaging of otherwise invisible defects in silicon, respectively. Procedures have been developed to optoelectronically reconstruct the resulting data on versatile relatively-compact setups and on wider-viewing-angle setups using multiple displays.

\section{Acknowledgements}

This research received funding from the European Community's Seventh Framework Programme FP7/2007-2013 under grant agreement no. 216105.

\section{References}

1. L. Onural, F. Yaraş, H. Kang, "Digital holographic three-dimensional video displays," Proc. IEEE 98, 1-14 (2011).

2. J. Mundt and T. Kreis, "Digital holographic recording and reconstruction of large scale objects for metrology and display, Opt. Eng. 49, 125801 (2010).

3. M. Paturzo, P. Memmolo, A. Finizio, R. Näsänen, T.J. Naughton and P. Ferraro, "Holographic display of synthetic 3D dynamic scene," 3D Research 1, 31-35 (2010).

4. M. Paturzo, A. Pelagotti, A. Finizio, L. Miccio, M. Locatelli, A. Gertrude, P. Poggi, R. Meucci and P. Ferraro, "Optical reconstruction of digital holograms recorded at $10.6 \mu \mathrm{m}$ : route for 3D imaging at long infrared wavelengths," Opt. Lett. 35, 2112-2114 (2010).

5. T. Colomb, N. Pavillon, J. Kühn, E. Cuche, C. Depeursinge and Y. Emery, "Extended depth-of-focus by digital holographic microscopy," Opt. Lett. 35, 1840-1842 (2010).

6. N. Pavillon, C. Arfire, I. Bergoënd and C. Depeursinge, "Iterative method for zero-order suppression in off-axis digital holography," Opt. Express 18, 15318-15331 (2010).

7. F. Yaraş, H. Kang and L. Onural, "State of the art in holographic displays: a survey," J. Disp. Technol. 6, 443-454 (2010). 
8. A. Pelagotti, M Locatelli, A.G. Geltrude, P. Poggi, R. Meucci,M. Paturzo, L. Miccio and P. Ferraro, "Reliability of 3D imaging by digital holography at long IR wavelength,” J. Disp. Technol. 6, 465-471 (2010).

9. M. Paturzo, P. Memmolo, A. Finizio, R. Näsänen, T.J. Naughton and P. Ferraro, "Synthesis and display of dynamic holographic 3D scenes with real-world objects," Opt. Express 18, 8806-8815 (2010).

10. M. Paturzo, F. Merola and P. Ferraro, "Multi-imaging capabilities of a 2D diffraction grating in combination with digital holography," Opt. Lett. 35, 1010-1012 (2010).

11. T. Colomb, S. Krivec, H. Hutter, A.A. Akatay, N. Pavillon, F. Montfort, E. Cuche, J. Kühn, C. Depeursinge and Y. Emery, "Digital holographic reflectometry," Opt. Express 18 3719-3731 (2010).

12. D.P. Kelly, D.S. Monaghan, N. Pandey, T. Kozacki, A. Michalkiewicz, G. Finke, B.M. Hennelly and M. Kujawinska, "Digital holographic capture and opto-electronic reconstruction for 3D displays," Hindawi International Journal of Digital Multimedia Broadcasting 2010, 759323 (2010).

13. K.M. Molony, B.M. Hennelly, D.P. Kelly and T.J. Naughton, "Reconstruction algorithms applied to in-line Gabor digital holographic microscopy," Opt. Commun. 283, 903-909 (2009).

14. M. Paturzo, P. Memmolo, A. Tulino, A. Finizio and P. Ferraro, "Investigation of angular multiplexing and demultiplexing of digital holograms recorded in microscope configuration," Opt. Express 17, 8709-8718 (2009).

15. L. Miccio, A. Finizio, S. Grilli, V. Vespini, M. Paturzo, S. De Nicola and P. Ferraro, "Tunable liquid microlens arrays in electrode-less configuration and their accurate characterization by interference microscopy," Opt. Express 17, 2487-2499 (2009).

16. L. Miccio, M. Paturzo, S. Grilli, V. Vespini and P. Ferraro, "Hemicylindrical and toroidal liquid microlens formed by pyro-electro-wetting," Opt. Lett. 34, 1075-1077 (2009).

17. P. Maddaloni, M. Paturzo, P. Ferraro, P. Malara, P. De Natale, M. Gioffre, G. Coppola and M. Iodice, "Midinfrared tunable two-dimensional Talbot array illuminator," Appl. Phys. Lett. 94, 121105 (2009).

18. P. Ferraro, M. Paturzo, P. Memmolo and A. Finizio, "Controlling depth of focus in 3D image reconstructions by flexible and adaptive deformation of digital holograms," Opt. Lett. 34 2787-2789 (2009).

19. M. Paturzo and P. Ferraro, "Creating an extended focus image of a tilted object in Fourier digital holography," Opt. Express 17, 20546-20552 (2009).

20. M. Paturzo and P. Ferraro, "Correct self-assembling of spatial frequencies in super-resolution synthetic aperture digital holography,” Opt. Lett. 34, 3650-3652 (2009).

21. H. Kang, F. Yaraş and L. Onural, "Graphics processing unit accelerated computation of digital holograms," Appl. Opt. 48, H137-H143 (2009).

22. D.S. Monaghan, D.P. Kelly, N. Pandey and B.M. Hennelly, "Twin removal in digital holography using diffuse illumination," Opt. Lett. 34, 3610-3612 (2009).

23. F. Yaraş, H. Kang and L. Onural, "Real-time phase-only color holographic video display system using LED illumination," Appl. Opt. 48, H48-H53 (2009).

24. J.E. Ward, D.P. Kelly, B.M. Hennelly and J.T. Sheridan, "Comment on the paper: H.-E. Hwang, P. Han, Theoretical analysis for surface tilt and translation detection based on speckle photography in the Fresnel domain," Opt. Commun. 282, 4358-4360 (2009).

25. A. Michalkiewicz and M. Kujawinska, "Optoelektroniczna rekonstrukcja hologramów cyfrowych," Elektronika 1, 120-128 (2009).

26. J. Ward, D.P. Kelly and J.T. Sheridan, "Three-dimensional speckle size on generalized optical systems with limiting apertures,” J. Opt. Soc. Am. A 26, 1855-1864 (2009).

27. D.P. Kelly, B.M. Hennelly, N. Pandey, T.J. Naughton and W.T. Rhodes, "Resolution limits in practical digital holographic systems," Opt. Eng. 48, 095801 (2009).

28. S.B. Hasan and T. Kozacki, "Method for enhancing resolution of holographic displays," Photonics Letters of Poland 1, 193-195 (2009).

29. M. Paturzo, P. Memmolo, L. Miccio, A. Finizio, P. Ferraro, A. Tulino and B. Javidi, "Numerical multiplexing and demultiplexing of digital holographic information for remote reconstruction in amplitude and phase," Opt. Lett. 33, 2629-2631 (2008).

30. S. Grilli, L. Miccio, V. Vespini, A. Finizio, S. De Nicola and P. Ferraro, "Liquid micro-lens array activated by selective electrowetting on lithium niobate substrates," Opt. Express 16, 8084-8093 (2008).

31. M. Paturzo, F. Merola, S. Grilli, S. De Nicola, A. Finizio and P. Ferraro, "Super-resolution in digital holography by a two-dimensional dynamic phase grating," Opt. Express 16, 17107-17118 (2008). 